\title{
Markers of inflammation in periodontal diseases
}

\author{
MAŁGORZATA NĘDZI-GÓRA ${ }^{l}$, JOLANTA KOSTRZEWA-JANICKA ${ }^{2}$, RENATA GÓRSKA ${ }^{l}$
}

${ }^{1}$ Department of Periodontology and Oral Diseases, Medical University of Warsaw, Poland

${ }^{2}$ Department of Prosthodontics, Medical University of Warsaw, Poland

\begin{abstract}
Periodontitis is a disease of chronic, progressive course and multifactorial etiology. Traditional diagnosis of periodontal disease is based on clinical and radiological examinations. However, clinical experience has shown that such diagnosis is not always sufficient. Numerous studies have attempted to identify - in gingival crevicular fluid, gingival tissue, saliva, and peripheral blood - various substances of both bacterial origin and derived from host cells, which would be pre-clinical indicators of disease progression. A certain level of such markers, or a change in their level within periodontium would be closely correlated with the severity of the disease. In order to determine that a given enzyme or cytokine may be a marker of inflammation, its role in both physiology and pathology of periodontal tissues should be thoroughly understood and analyzed. Currently, interleukin-1 $\beta$, prostaglandin $E_{2}$, elastase and metalloproteinase 8 are considered the most significant immunological indicators. Extending the diagnostic procedures and treatment monitoring by methods based on determination of the level of inflammatory mediators in gingival crevicular fluid or in saliva may facilitate diagnosis, increase treatment effectiveness, and provide data on the pathomechanism of periodontal diseases.
\end{abstract}

Key words: periodontitis, inflammation, markers.

(Centr Eur J Immunol 2013; 38 (3): 363-366)

\section{Introduction}

Epidemiological studies have indicated that in Western Europe, $36 \%$ of people aged $35-44$ years have a moderately severe, and about $10 \%$ - a severe form of periodontitis [1]. These proportions are higher in Eastern Europe and equal $45 \%$ and $30-40 \%$, respectively. Research conducted by Górska et al. [2] showed that advanced periodontitis affects $18 \%$ of adult Poles. These data are shocking, particularly when taking into account local effects, such as loss of teeth, as well as systemic implications, such as association of untreated periodontal inflammation with cardiovascular diseases.

Traditional diagnosis of periodontal disease is based on clinical and radiological examinations. However, clinical experience has shown that such diagnosis is not always sufficient. Observation of changes in indicators such as clinical attachment loss (CAL) and radiographic evaluation of alveolar bone loss (BL) over time, is unfortunately possible only after a few millimeters' loss of clinical attachment (retrospective diagnosis). Therefore, for many years studies have been conducted in order to develop diagnostic tests, allowing prediction of disease activity. Such tests would help to identify patients (or specific locations in patient's periodontium) that are particularly vulnerable to occurrence and rapid progression of periodontal disease. Such extended diagnostic procedures are particularly important for patients with possible periodontal lesions which could occur at a young age, or for detection of the disease progression risk at the subclinical level.

Numerous studies concerned determination of specific species (strains) of bacteria present in dental plaque, which would be responsible for a more rapid progression of periodontal disease or its occurrence at a very young age. Research carried out by Sokransky et al. [3] showed, however, that in the case of both chronic and aggressive periodontitis we are dealing - at most - with the so-called specific bacterial complexes, but none of the known bacteria is pathognomonic for a given disease. Moreover, in the light of recent studies it is known that anaerobic bacteria such

Correspondence: Małgorzata Nędzi-Góra, Department of Periodontology and Oral Diseases, Medical University of Warsaw, Miodowa 18, 00-246 Warsaw, e-mail: mnedzi-gora@wp.pl 
as Porphyromonas gingivalis, Prevotella intermedia, and Treponema denticola are responsible only for initiating and sustaining inflammation in periodontium. There is no doubt, however, that the mere direct action of the bacterial factor by metabolism products or bacterial enzymes would not be able to cause such significant destruction of epithelium, connective tissue and alveolar bone, which is characteristic in the course of periodontitis. Destruction of periodontal tissues, which are necessary for proper functioning of the tooth in the oral cavity, is largely caused by so-called indirect mechanisms, involving activation of the host immune response, which consequently leads to destruction of periodontal tissues.

Therefore, from a clinical point of view, a more useful method seems to be identification of inflammatory markers in material derived from the patient. A certain level of such markers, or a change in their level within periodontium would be closely correlated with the severity of the disease. In order to determine that a given enzyme or cytokine may be a marker of inflammation, its role in both physiology and pathology of periodontal tissues, should be thoroughly understood and analyzed.

\section{Pathomechanism of periodontal disease}

In the latest (1999) valid division of periodontal disease, three main groups of inflammatory periodontal diseases are distinguished: gingivitis caused by dental plaque, chronic periodontitis and aggressive periodontitis. Although each of the diseases is characterized by a different pathomechanism and clinical course, in each case a fundamental role is played by immuno-inflammatory mechanisms constituting a response to the bacterial factor.

According to a theory by Page [4], anaerobic bacteria initiate the inflammatory process in periodontium, by initiating a cascade of immuno-inflammatory reactions. Accumulation of factors of virulent bacteria and bacterial enzymes' products in tissues adjacent to the periodontal pocket (internal epithelium and subepithelial connective tissue) causes vasodilation and congestion of gingival tissue. In such case, redness, swelling, and spontaneous or stimulated bleeding of gingiva are clinically observed. Released blood flow promotes increased exudate - referred to as gingival crevicular fluid (GCF), and migration of inflammatory cells towards the periodontal pocket. Chemotaxis is also promoted by high concentrations of bacterial toxins (including lipopolysaccharides - LPS) as well as products of tissue destruction by either bacterial enzymes or host's enzymes. Bacterial lipopolysaccharides, which can penetrate from the periodontal pocket to tissues surrounding the tooth, are also able to activate complement in an alternative way, whereas bacterial antigens coated by complement components are absorbed by cells of the first line of defense, which are present in periodontium and those which arrived to the site of periodontal inflammation. Virulent factors of anaerobic bacteria, such as LPS, also have the ability through CD14 receptors on neutrophils - to initiate degranulation of inflammatory infiltration cells, such as PMN. As a result of this process, enzymes, among other things, are released in the region of tissues of epithelial and connective tissue attachment. These enzymes (elastase, metalloproteinases) have the ability to destroy the connective tissue, which - together with the bone - is the primary tissue responsible for the proper maintenance of the tooth in the alveolus. Operation of bacterial virulence factors results also in activation of a cascade of inflammation reactions within the mucous membranes of host cells, which cause changes in arachidonic acid, to typical products of inflammation, such as prostaglandins and leukotrienes. They are responsible for initiating destruction of the alveolar bone.

All the above processes are regulated by cytokines. They constitute a key element of immunoregulation in the pathomechanism of periodontal disease. Produced in healthy tissue, they condition its proper functioning. They are secreted by most cells present in periodontium and are responsible for transmission of signals between fixed cells and inflammatory infiltration cells. The release of proper cytokines in a determined amount depends not only on stimulating factors such as lipopolysaccharides, but also on activation of appropriate genes. The main mediator of periodontal tissue destruction seems to be, as in other inflammatory diseases, uncontrolled release of IL- $1 \beta$. It occurs in response to induction by periodontal pathogenic bacteria, present in the periodontal pocket, such as $P$. gingivalis and is considered to be the main factor causing periodontal tissue destruction.

\section{Mediators of inflammation in periodontal diseases}

Inflammatory mediators were assessed in various material collected from patients with periodontal disease. Determination of inflammatory mediators in peripheral blood (plasma, serum) allows an analysis of the relationship between periodontal disease with systemic diseases, but does not reflect unambiguously the current status of periodontal tissues. Joshipura et al. [5] used a multivariate regression model to associate periodontitis with a high CRP level in serum. Many systemic factors affect the level of inflammatory mediators, such as CRP in peripheral blood. Nonetheless, a study by D'Aiuto et al. [6] showed a significant reduction in CRP and IL-6 levels in serum as a result of periodontal treatment. Also own studies by Górska et al. [7] showed significant differences in MMP-8 concentration in peripheral blood serum in a group of healthy individuals and patients with chronic periodontitis.

Collecting tissue samples from the periodontal pocket area seems to be a good method in the study on periodontal disease pathomechanism, yet it is not popular in clinical trials. Korostoff et al. [8] demonstrated an expression of latent forms of MMP-2 and MMP-9 in gingival biopsies 
taken from healthy individuals and patients with periodontitis. In turn, the active form of MMP-2 was present only in material collected from patients with periodontitis [9].

An increased expression of proteolytic enzymes and inflammatory enzymes in periodontal tissues (both periodontal tissue cells and inflammatory infiltration cells) in the course of periodontitis can cause increased levels of these enzymes in body fluids. Gingival crevicular fluid, whose composition reflects the course of inflammation in periodontal tissues, seems to be credible material.

Research by Masada et al. [10] demonstrated elevated concentrations of IL-1 $\beta$ in GCF collected from diseased sites in periodontium, compared to concentrations in healthy areas. The concentration of the cytokine decreased after scaling and root surface planing, even if it did not correlate with pocket depth change. Similar results were obtained by Hou et al. [11]. They observed that the amount of IL-1 $\beta$ is closely associated with progression of lesions in periodontium. Reinhardt et al. [12] demonstrated that an increased level of IL-1 $\beta$ is closely associated with the presence of three bacterial species in the examined pockets: Actinobacillus actinomycetemcomitans, Porphyromonas gingivalis and Eikenella corrodens.

A study by Preiss et al. [13] demonstrated that the amount of IL-1 $\beta$ in gingival crevicular fluid in patients with periodontitis is significantly higher than in healthy individuals. This was confirmed by Tsai et al. [14], who also concluded that it is reduced as a result of conducting the initial phase of periodontal treatment. The amount of IL- $1 \beta$ was also correlated with clinical parameters [15]. Another study by Hou et al. [11] suggested that the amount of IL-1 $\beta$ in GCF is closely associated with the patient's periodontal status. Engebredson et al. [16] observed that increased levels of IL- $1 \beta$ in gingival crevicular fluid in patients with severe periodontal disease, is also found in shallow pockets, which confirms the role of the genetic factor associated with an increased expression of IL- $1 \beta$ in the pathogenesis of chronic periodontitis.

Research by Atilla et al. [17] showed that gingival crevicular fluid of patients with periodontitis has significantly higher concentrations of MMP-8 and MMP-9 compared to healthy individuals. Chen et al. [18] observed that a concentration of MMP- 8 in gingival crevicular fluid is positively correlated with the plaque index and bleeding index, whereas the total amount of MMP-8 in GCF is also correlated with the depth of periodontal pockets in patients with periodontitis.

An increased level of elastase was also observed in gingival crevicular fluid of patients with periodontitis compared with healthy controls. Eley et al. and Cox et al. [19, 20] demonstrated that elastase concentration in GCF correlates with clinical indicators of progressive periodontitis and decreases significantly after periodontal treatment. In addition, higher elastase levels in gingival crevicular fluid were also found in patients with so-called refractory periodonti- tis compared to patients with a similar degree of periodontitis severity who responded positively to treatment. Moreover, a significantly higher concentration of elastase was observed in areas demonstrating periodontal disease progression [21] and a risk of the progressive alveolar bone loss [22]. A study by Meile et al. [23] showed that intensive hygienic procedures lead to reduced elastase levels in GCF.

Jin et al. [24], and Söder et al. [25] studied relationships between the elastase activity and $\mathrm{PGE}_{2}$ level in gingival crevicular fluid on one hand, and the presence of periodontal pathogenic bacteria (Actinobacillus actinomycetemcomitans, Bacteroides forsythus, Porphyromonas gingivalis, Prevotella intermedia, Treponema denticola) on the other hand, in patients with untreated periodontitis. They demonstrated that a local immune response to periopathogens varies depending on intensity of the inflammatory response measured by elastase and $\mathrm{PGE}_{2}$ levels in gingival crevicular fluid.

According to Offenbacher et al. [26], an elevated level of $\mathrm{PGE}_{2}$ in gingival crevicular fluid collected from lesioned sites corresponds to the concentration causing bone tissue resorption in vitro. Studies by Haesman et al. [27] showed that $\mathrm{PGE}_{2}$ concentrations in GCF of healthy individuals are low and they increase in the course of gingivitis. Moreover, patients with periodontitis demonstrate higher $\mathrm{PGE}_{2}$ levels in GCF than those with gingivitis [28]. Also in untreated sites with a progressive clinical attachment loss, a significant increase in the $\mathrm{PGE}_{2}$ level in GCF was observed [29].

Gingival crevicular fluid, however, is not an easy material to collect, especially for analysis, due to very small volume of fluid intake. Measurement devices for small volumes of liquid which are available on the market, such as Periotron 8000 , make it possible to analyze the concentration of selected mediators, however, such methods are very time-consuming and costly.

Saliva seems to be a material which is simple to collect and analyze. Although the concentration of inflammatory mediators in this material is several times lower than in gingival crevicular fluid, sensitivity of presently applied methods makes the issue less critical. Saliva seems to be a very good test material for substances derived from PMN cells. These cells infiltrate tissues surrounding a periodontal pocket, then penetrate into gingival crevicular fluid, and, consequently, to saliva. According to Uitto et al. [30], polymorphonuclear leukocytes (PMN) constitute the main source of salivary collagenases, such as MMP-8. Each milliliter of whole saliva contains from 100,000 to 500,000 PMN cells in various stages of degradation. They transfer into the oral cavity through gingival sulcus. Research by Gangbar et al. [31] showed that isolated parotid saliva and sublingual saliva virtually contain no collagenases, and only small quantities of them are found in saliva of edentulous patients. Our study [7] demonstrated increased levels of MMP-8 in saliva of patients with advanced periodontitis compared to patients with mild to moderate periodontitis and to healthy 
individuals. It was also shown that elastase concentration in saliva of patients with chronic periodontitis is significantly higher compared to those with healthy periodontium.

Multifactorial etiology of periodontitis makes causal treatment of some of its manifestations often impossible and inadequate. Extending the diagnostic procedures and treatment monitoring by methods based on determination of the level of inflammatory mediators in gingival crevicular fluid or in saliva may facilitate diagnosis, increase treatment effectiveness, and provide data on the pathomechanism of periodontal diseases.

\section{References}

1. Sheiham A, Netuveli GS (2002): Periodontal diseases in Europe. Periodontol 29: 104-121.

2. Górska, Pietruszka M, Dembowska E, Wysokińska-Miszczuk J, et al. (2012): Częstość występowania chorób przyzębia u osób w wieku 35-44 lat w populacji dużych aglomeracji miejskich. Dent Med Probl 49: 19-27.

3. Socransky SS, Haffajee AD, Cugini MA (1998): Microbial complexes in subgingival plaque. J Clin Periodontol 25: 134-144.

4. Page RC (1991): The role of inflammatory mediators in the pathogenesis of periodontal disease. J Periodontal Res 26 (3 Pt 2): 230-242.

5. Joshipura KJ, Wand HC, Merchant AT, Rimm EB (2004): Periodontal disease and biomarkers related to cardiovascular disease. J Dent Res 83: 151-155.

6. D'Aiuto F, Parkar M, Andreou G, et al. (2004): Periodontitis and systemic inflammation: control of the local infection is associated with a reduction in serum inflammatory markers. J Dent Res 83: 156-160.

7. Górska R, Nedzi-Góra M (2006): The effects of the initial treatment phase and of adjunctive low-dose doxycycline therapy on clinical parameters and MMP-8, MMP-9, and TIMP-1 levels in the saliva and peripheral blood of patients with chronic periodontitis. Arch Immunol Ther Exp (Warsz) 54: 419-426.

8. Korostoff JM, Wang JF, Sarment DP, et al. (2000): Analysis of in situ protease activity in chronic adult periodontitis patients: expression of activated MMP-2 and a $40 \mathrm{kDa}$ serine protease. J Periodontol 71: 353-360.

9. Kuźmiński A, Przybyszewski M, Graczyk M, Kartuzi Z (2012): The role of extracellular matrix metalloproteinases and their inhibitors in allergic diseases. Postep Derm Alergol 29: 384-389.

10. Masada MP, Persson R, Kenney JS, et al. (1990): Measurement of interleukin-1 alpha and -1 beta in gingival crevicular fluid: implications for the pathogenesis of periodontal disease. J Periodontal Res 25: 156-163.

11. Hou LT, Liu CM, Rossomando EF (1995): Crevicular interleukin-1 beta in moderate and severe periodontitis patients and the effect of phase I periodontal treatment. J Clin Periodontol 22: $162-167$.

12. Reinhardt RA, Masada MP, Kaldahl WB, et al. (1993): Gingival fluid IL-1 and IL-6 levels in refractory periodontitis. J Clin Periodontol 20: 225-231.

13. Preiss DS, Meyle J (1994): Interleukin-1 beta concentration of gingival crevicular fluid. J Periodontol 65: 423-428.

14. Tsai CC, Ho YP, Chen CC (1995): Levels of interleukin-1 beta and interleukin- 8 in gingival crevicular fluids in adult periodontitis. J Periodontol 66: 852-859.
15. Ishihara Y, Nishihara T, Kuroyanagi T, et al. (1997): Gingival crevicular interleukin-1 and interleukin-1 receptor antagonist levels in periodontally healthy and diseased sites. J Periodontal Res 32: 524-529.

16. Engebretson SP, Grbic JT, Singer R, Lamster IB (2002): GCF IL-1beta profiles in periodontal disease. J Clin Periodontol 29: 48-53.

17. Atilla G, Sorsa T, Rönka H, Emingil G (2001): Matrix metalloproteinases (MMP-8 and -9) and neutrophil elastase in gingival crevicular fluid of cyclosporin-treated patients. J Periodontol 72: 354-360.

18. Chen HY, Cox SW, Eley BM, et al. (2000): Matrix metalloproteinase- 8 levels and elastase activities in gingival crevicular fluid from chronic adult periodontitis patients. J Clin Periodontol 27: 366-369.

19. Eley BM, Cox SW (1992): Correlation of gingival crevicular fluid proteases with clinical and radiological measurements of periodontal attachment loss. J Dent 20: 90-99.

20. Cox SW, Eley BM (1992): Cathepsin B/L-, elastase-, tryptase, trypsin- and dipeptidyl peptidase IV-like activities in gingival crevicular fluid. A comparison of levels before and after basic periodontal treatment of chronic periodontitis patients. J Clin Periodontol 19: 333-339.

21. Palcanis KG, Larjava IK, Wells BR, et al. (1992): Elastase as an indicator of periodontal disease progression. J Periodontol 63: 237-242.

22. Armitage GC, Jeffcoat MK, Chadwick DE, et al. (1994): Longitudinal evaluation of elastase as a marker for the progression of periodontitis. J Periodontol 65: 120-128.

23. Meyle J, Zell S, Brecx M, Heller W (1992): Influence of oral hygiene on elastase concentration of gingival crevicular fluid. J Periodontal Res 27: 226-231.

24. Jin LJ, Söder PO, Leung WK, et al. (1999): Granulocyte elastase activity and PGE2 levels in gingival crevicular fluid in relation to the presence of subgingival periodontopathogens in subjects with untreated adult periodontitis. J Clin Periodontol 26: 531-540.

25. Söder B, Jin LJ, Wickholm S (2002): Granulocyte elastase, matrix metalloproteinase-8 and prostaglandin E2 in gingival crevicular fluid in matched clinical sites in smokers and nonsmokers with persistent periodontitis. J Clin Periodontol 29: 384-391.

26. Offenbacher S, Collins JG, Heasman PA (1993): Diagnostic potential of host response mediators. Adv Dent Res 7: 175-181.

27. Heasman PA, Collins JG, Offenbacher S (1993): Changes in crevicular fluid levels of interleukin-1 beta, leukotriene B4, prostaglandin E2, thromboxane B2 and tumour necrosis factor alpha in experimental gingivitis in humans. J Periodontal Res 28: 241-247.

28. Offenbacher S, Heasman PA, Collins JG (1993): Modulation of host PGE2 secretion as a determinant of periodontal disease expression. J Periodontol 64 (5 Suppl): 432-444.

29. Offenbacher S, Odle BM, Van Dyke TE (1986): The use of crevicular fluid prostaglandin E2 levels as a predictor of periodontal attachment loss. J Periodontal Res 21: 101-112.

30. Uitto VJ, Suomalainen K, Sorsa T (1990): Salivary collagenase. Origin, characteristics and relationship to periodontal health. J Periodontal Res 25: 135-142.

31. Gangbar S, Overall CM, McCulloch CA, Sodek J (1990): Identification of polymorphonuclear leukocyte collagenase and gelatinase activities in mouthrinse samples: correlation with periodontal disease activity in adult and juvenile periodontitis. J Periodontal Res 25: 257-267. 